\title{
Quem é/deve ser o professor da escola indígena: uma discussão introdutória
}

\author{
Letícia Fraga \\ Universidade Estadual de Ponta Grossa (UEPG), Ponta Grossa, Paraná, Brasil \\ leticiafraga@gmail.com
}

DOI: http://dx.doi.org/10.21165/el.v46i2.1754

\begin{abstract}
Resumo
Este texto tem o objetivo de apresentar uma discussão inicial sobre o perfil do professor da escola indígena, a partir do Referencial Curricular Nacional para Escolas Indígenas (RCNEI/BRASIL, 1998) e da realidade das escolas indígenas do estado do Paraná. Defende-se que, independentemente do considerado ideal pelo RCNEI, é preciso que os professores que atuam nessas instituições, indígenas ou não-indígenas, tenham formação inicial adequada para exercer seus papéis, garantindo uma "educação escolar bilíngue e intercultural aos povos indígenas" (BRASIL, 1996, Art. 78).
\end{abstract}

Palavras-chave: educação escolar indígena; formação de professores; políticas linguísticas.

Who is / should be the teacher of the indigenous school: an introductory discussion

\begin{abstract}
This paper intend to introduce an initial discussion about the profile of the teacher in indigenous schools from the Referencial Curricular Nacional para Escolas Indigenas [Brazilian Curricular Reference for Indigenous Schools] (RCNEI/BRASIL, 1998) and the reality of the indigenous schools in the state of Paraná. We believe that, beyond what the RCNEI considers as ideal, is necessary that the teachers who act in these institutions, indigenous or non-indigenous, have an adequate initial formation to play their role properly, ensuring an "bilingual and intercultural education to the indigenous folk" (BRASIL, 1996, Art. 78).
\end{abstract}

Keywords: indigenous school education; teacher education; linguistic policies.

Desde 2008, nossos interesses de pesquisa têm se voltado ao exame da condição linguística do estado do Paraná, mais especificamente de regiões linguisticamente complexas, em que há indícios de bi/multilinguismo apontados por órgãos oficiais, como IBGE (BRASIL, 2012) ${ }^{1}$ ou trabalhos acadêmicos.

Como exemplos de contextos linguisticamente complexos que já investigamos, citamos comunidades indígenas, colônias de imigrantes, comunidades quilombolas/negro-rurais, comunidades escolares periféricas, contextos de educação formal em situação de privação de liberdade, dentre outros. Alguns dos trabalhos que desenvolvemos foram inclusive submetidos à avaliação por agências de fomento e contemplados com financiamento ${ }^{2}$.

\footnotetext{
1 "O Censo de 2010 foi o primeiro da história brasileira para o qual os entrevistados responderam a questões sobre a) pertencimento étnico (que poderia ser autodeclarado ou "considerado") e b) uso/não uso de língua indígena e portuguesa em domicílio" (FRAGA; TASSO, 2016, p. 169).

${ }^{2}$ Os projetos a que me refiro são os seguintes: a) "Políticas linguísticas e ensino de língua na região dos Campos Gerais/PR", desenvolvido entre 2011 e 2013, financiado pela Fundação Araucária; b) "Políticas educacionais e ensino de língua em Mangueirinha/PR: revitalização sociocultural e linguística da
} 
Em relação aos contextos investigados, destacamos o indígena, em que vimos realizando pesquisas desde 2012, mais especificamente observando a forma como as escolas situadas nesses contextos lidam com suas realidades e administram suas especificidades. No que diz respeito à escola indígena, é ponto pacífico que ainda há muito que se observar: sua gestão, o currículo, a formação do corpo docente, dentre outros.

Neste texto, porém, por razões de escopo, optamos por focar a discussão em apenas um ponto, bastante polêmico, inclusive, em relação às escolas indígenas, que é o perfil do professor dessa instituição.

Consideramos o debate relevante pelo fato de a grande maioria dos trabalhos sobre educação escolar indígena, quando tratam de formação inicial ou continuada de professores, discutirem, quase exclusivamente, a presença (ou necessidade da presença) do professor indigena, o que é absolutamente compreensível levando em conta que a '(trans)formação de índios em professores' (GRUPIONI, 2006) é um princípio sustentado, implícita ou explicitamente, pelas principais políticas que orientam as bases da Educação Escolar Indígena no Brasil, como a Constituição, a Lei de Diretrizes e Bases da Educação Nacional/Lei 9394, o Plano Nacional de Educação/Lei 10.172, as Diretrizes Curriculares Nacionais da Educação Escolar Indígena, o Referencial Curricular Nacional para as Escolas Indígenas, a Resolução 3/99 e o Parecer 14/99 do CNE, dentre outras.

No entanto, essas mesmas políticas, que definem a escola indígena ideal protagonizada por indígenas, reconhecem que, por uma série de razões, esse protagonismo ainda está longe de ser dar efetivamente. Ou seja, embora a lei exista, a realidade atual da educação brasileira é diferente, mostrando que União, estados e municípios não conseguem cumprir suas responsabilidades minimamente. Nesse caso, inclusive,

[...] se [mostrando] pouco permeáveis às mudanças reclamadas pelos povos indígenas. Tais instâncias, via de regra, não contam com quadros técnicos qualificados, políticas de longa duração são preteridas em prol de ações pontuais e fragmentadas, que não encontram nexo na rotatividade de cargos e mudanças de políticas, que tanto caracterizam a administração pública no Brasil. Face à burocracia governamental, a tão propalada participação indígena fica mais no discurso que na prática (GRUPIONI, 2006, p. 64).

Como, então, deve se dar o debate sobre o perfil do professor da escola indígena? Afinal, na escola indígena só cabem professores indígenas? A presença de professores não-indígenas causaria problemas à escola?

Trouxemos essas questões assim, de forma bastante simplista, porque em geral é dessa forma que "curiosos" e mesmo colegas nos expõem suas dúvidas quanto ao tema.

identidade Kaingang”, desenvolvido entre 2012 e 2015, financiado pela Fundação Araucária); c) "Formação continuada de professores de língua em contextos bi/multilíngues paranaenses", desenvolvido entre 2012 e 2016, financiado pelo CNPq; d) "Políticas educacionais e ensino de língua em terras indígenas paranaenses: formação continuada de professores de língua em contextos bi/multilíngues", iniciado em 2013, financiado pelo CNPq; e) "Revitalização sociocultural e linguística em terras indígenas paranaenses: estudos sobre políticas educacionais e ensino de língua”, iniciado em 2014, financiado pelo CNPq. 
Mas já de início defendemos que a discussão não caminha nessa direção, por mais que os questionamentos sejam/tenham sido colocados dessa forma.

Não é uma questão de 'sim' ou 'não'. É preciso, no mínimo, considerar a discussão com base no que é tido como ideal e/ou real. Pretendemos, ao menos de forma introdutória, insistimos, abordar esses dois pontos de vista: o ideal, a partir das orientações do RCNEI, e o real, a partir de dados da Secretaria de Educação do estado do Paraná, relativos à situação das escolas indígenas paranaenses no que diz respeito a quem são os professores que hoje estão atuando nesse contexto.

Segundo as orientações do RCNEI (1998), o professor ideal para a escola indígena é o professor indígena. Somente ele é capaz de garantir que a escola indígena seja:

5.1.1 Comunitária: Porque conduzida pela comunidade indígena, de acordo com seus projetos, suas concepções e seus princípios. Isto se refere tanto ao currículo quanto aos modos de administrá-la. Inclui liberdade de decisão quanto ao calendário escolar, à pedagogia, aos objetivos, aos conteúdos, aos espaços e momentos utilizados para a educação escolarizada. 5.1.2 Intercultural: Porque deve reconhecer e manter a diversidade cultural e linguística; promover uma situação de comunicação entre experiências socioculturais, linguísticas e históricas diferentes, não considerando uma cultura superior à outra; estimular o entendimento e o respeito entre seres humanos de identidades étnicas diferentes, ainda que se reconheça que tais relações vêm ocorrendo historicamente em contextos de desigualdade social e política. 5.1.3 Bilíngue/multilíngue: Porque as tradições culturais, os conhecimentos acumulados, a educação das gerações mais novas, as crenças, o pensamento e a prática religiosos, as representações simbólicas, a organização política, os projetos de futuro, enfim, a reprodução sociocultural das sociedades indígenas são, na maioria dos casos, manifestados através do uso de mais de uma língua. Mesmo os povos indígenas que são hoje monolíngues em língua portuguesa continuam a usar a língua de seus ancestrais como um símbolo poderoso para onde confluem muitos de seus traços identificatórios, constituindo, assim, um quadro de bilinguismo simbólico importante. 5.1.4. Específica e diferenciada: Porque concebida e planejada como reflexo das aspirações particulares de povo indígena e com autonomia em relação a determinados aspectos que regem o funcionamento e orientação da escola não-indígena (BRASIL, 1998, p. 24-25).

Já a Constituição da República (1988) e a LDB (1996) não falam explicitamente na necessidade de o professor da escola indígena ser indígena, mas mencionam a obrigação de o Estado brasileiro ofertar "[...] educação escolar bilíngue e intercultural aos povos indígenas" (BRASIL, 1996, Art. 78), o que, por dedução, estaria 'garantido' caso o professor fosse indígena.

Há várias razões para o fato de o professor da escola indígena não ser obrigatoriamente indígena, mas a mais preocupante é que, se existisse, essa exigência inviabilizaria o funcionamento das escolas indígenas, já que não há, em nenhum estado brasileiro, professores indígenas formados em nível superior em número suficiente para atender toda a demanda de professores de Educação Básica.

$\mathrm{Na}$ verdade, a própria exigência de acesso ao ensino superior pelos indígenas deu-se muito recentemente, após a chamada 'reforma da educação escolar indígena', em 1991, ano em que a educação indígena foi contemplada pela Constituição Brasileira como responsabilidade do governo (CAVALCANTI, 1999). E a organização do 
movimento indígena nesse sentido só se impôs mais efetivamente depois que algumas universidades reconheceram que, sozinhas, não 'dariam conta do recado', já que mesmo desenvolvendo projetos de assessoria e parceria com comunidades, projetos de extensão e também de pesquisas e ensino, não atingiam os resultados necessários, principalmente se considerarmos que poucos projetos têm/tinham como objetivo incentivar os professores indígenas a serem pesquisadores em suas próprias comunidades (KONDO, 2013).

No estado do Paraná, essa questão parece mais urgente se se considera que as políticas afirmativas voltadas ao acesso ao ensino superior pelas populações indígenas locais se resumem à "reserva de vagas para indígenas nas Universidades Estaduais" (PARANÁ, 2001; 2006) e na Universidade Federal do Paraná, dentro dos cursos já existentes nessas instituições, diferentemente do que ocorre em outros 20 estados brasileiros, nos quais as políticas de acesso ao ensino superior incluem a oferta de cursos específicos voltados à formação de professores indígenas.

O fato de, no estado, as políticas de acesso ao ensino superior por indígenas terem restrições (no sentido de não incluir a oferta de um curso específico, por exemplo) tem muitas consequências. E talvez uma das mais significativas seja a de impor à educação escolar indígena uma grande dependência da presença de muitos professores não indígenas para continuarem funcionando. Reafirmando, as escolas indígenas no Paraná não subsistem sem a presença de professores e pedagogos não indígenas para completarem seus quadros.

No entanto, dizer que não há professores indígenas suficientes não significa dizer que não há nenhum. Para sermos mais exatos, dos 875 professores atuantes em escolas indígenas paranaenses, 353 são indígenas e 522, não. Em termos absolutos ${ }^{3}$, a proporção é de quatro para cada grupo de dez (FRAGA et al., 2014), distribuídos conforme se pode observar no Quadro 1 a seguir.

Quadro 1. Relação dos profissionais indígenas e não-indígenas das escolas indígenas, atuando em 2013

\begin{tabular}{|l|l|l|l|c|c|c|}
\hline \multicolumn{1}{|c|}{ NRE } & \multicolumn{1}{|c|}{ Município } & Terra indígena & \multicolumn{1}{c|}{ Escola } & Indígenas & $\begin{array}{c}\text { Não- } \\
\text { indígenas }\end{array}$ & Total \\
\hline $\begin{array}{l}\text { Área Metrop. } \\
\text { Norte }\end{array}$ & Piraquara & Araça'í & $\begin{array}{l}\text { E.E.I. Mbya } \\
\text { Arandu }\end{array}$ & 7 & 7 & 14 \\
\hline $\begin{array}{l}\text { Campo } \\
\text { Mourão }\end{array}$ & $\begin{array}{l}\text { Campo } \\
\text { Mourão }\end{array}$ & Verá Tupã'i & E.E.I. Tape Aviru & 2 & 0 & 2 \\
\hline $\begin{array}{l}\text { Cornélio } \\
\text { Procópio }\end{array}$ & Santa Amélia & Laranjinha & $\begin{array}{l}\text { E.E.I. Cacique } \\
\text { Tudja Nhanderu }\end{array}$ & 7 & 5 & 12 \\
\hline $\begin{array}{l}\text { Cornélio } \\
\text { Procópio }\end{array}$ & $\begin{array}{l}\text { São Jerônimo } \\
\text { da Serra }\end{array}$ & $\begin{array}{l}\text { São Jerônimo da } \\
\text { Serra }\end{array}$ & $\begin{array}{l}\text { C.E.I. Cacique } \\
\text { Kofej }\end{array}$ & 26 & 19 & 45 \\
\hline
\end{tabular}

\footnotetext{
3 Neste texto utilizaremos média simples, embora reconheçamos que há realidades completamente diferentes, como a da E.E.I. João Kavagtãn Vergílio, de Tamarana, que possui 23 professores indígenas e dois professores não-indígenas; a do C.E.I. Valdomiro Tupã Pires de Lima, de Chopinzinho, que possui quatro professores indígenas e 18 não-indígenas e a da E.E.I. Mbya Arandu, de Piraquara, que tem exatamente o mesmo número de professores indígenas e não indígenas: sete (FRAGA et al. 2013).
} 


\begin{tabular}{|c|c|c|c|c|c|c|}
\hline NRE & Município & Terra indígena & Escola & Indígenas & $\begin{array}{c}\text { Não- } \\
\text { indígenas }\end{array}$ & Total \\
\hline $\begin{array}{l}\text { Cornélio } \\
\text { Procópio }\end{array}$ & $\begin{array}{l}\text { São Jerônimo } \\
\text { da Serra }\end{array}$ & $\begin{array}{l}\text { Barão de } \\
\text { Antonina }\end{array}$ & $\begin{array}{l}\text { E.E.I. Cacique } \\
\text { Onofre Kanhgrén }\end{array}$ & 27 & 26 & 53 \\
\hline $\begin{array}{l}\text { Cornélio } \\
\text { Procópio }\end{array}$ & $\begin{array}{l}\text { São Jerônimo } \\
\text { da Serra }\end{array}$ & $\begin{array}{l}\text { Barão de } \\
\text { Antonina }\end{array}$ & $\begin{array}{l}\text { E.E.I. Índio Rael } \\
\text { Vynhkág }\end{array}$ & 5 & 7 & 12 \\
\hline $\begin{array}{l}\text { Foz do } \\
\text { Iguaçu }\end{array}$ & $\begin{array}{l}\text { São Miguel } \\
\text { do Iguaçu }\end{array}$ & Ocoy & $\begin{array}{l}\text { C. E.I. Teko } \\
\text { Ñemoingo }\end{array}$ & 16 & 29 & 45 \\
\hline Guarapuava & Turvo & Marrecas & $\begin{array}{l}\text { C.E.I. Cacique } \\
\text { Trajano Mrej Tar }\end{array}$ & 7 & 20 & 27 \\
\hline Guarapuava & Turvo & Koeju Porã & $\begin{array}{l}\text { E.E.I. Arandu } \\
\text { Pyahu }\end{array}$ & 5 & 3 & 8 \\
\hline Ibaiti & Tomazina & Pinhalzinho & E.E.I. Yvy Porã & 7 & 12 & 19 \\
\hline Irati & $\begin{array}{l}\text { Inácio } \\
\text { Martins }\end{array}$ & Rio D'areia & $\begin{array}{l}\text { E.E.I. Arandu } \\
\text { Mirin }\end{array}$ & 5 & 6 & 11 \\
\hline Ivaiporã & $\begin{array}{l}\text { Manoel } \\
\text { Ribas }\end{array}$ & Ivaí & $\begin{array}{l}\text { C.E.I. Cacique } \\
\text { Gregório Kaekchot }\end{array}$ & 13 & 70 & 83 \\
\hline Ivaiporã & $\begin{array}{l}\text { Cândido de } \\
\text { Abreu }\end{array}$ & Faxinal & $\begin{array}{l}\text { C.E.I. Professor } \\
\text { Sergio Krigrivaja } \\
\text { Lucas }\end{array}$ & 12 & 28 & 40 \\
\hline Jacarezinho & Abatiá & Ywy Porã & $\begin{array}{l}\text { E.E.I. Nimboeaty } \\
\text { Mborowitxa Awa } \\
\text { Tirope }\end{array}$ & 8 & 3 & 11 \\
\hline $\begin{array}{l}\text { Laranjeiras } \\
\text { do Sul }\end{array}$ & $\begin{array}{l}\text { Nova } \\
\text { Laranjeiras }\end{array}$ & $\begin{array}{l}\text { Rio das Cobras } \\
\text { (Sede) }\end{array}$ & $\begin{array}{l}\text { C.E.I. Rio das } \\
\text { Cobras }\end{array}$ & 5 & 30 & 35 \\
\hline $\begin{array}{l}\text { Laranjeiras } \\
\text { do Sul }\end{array}$ & $\begin{array}{l}\text { Nova } \\
\text { Laranjeiras }\end{array}$ & $\begin{array}{l}\text { Rio das Cobras } \\
\text { (Trevo) }\end{array}$ & $\begin{array}{l}\text { C.E.I. Professor } \\
\text { Candoca Tãnhprág } \\
\text { Fidêncio }\end{array}$ & 12 & 17 & 29 \\
\hline $\begin{array}{l}\text { Laranjeiras } \\
\text { do Sul }\end{array}$ & $\begin{array}{l}\text { Nova } \\
\text { Laranjeiras }\end{array}$ & $\begin{array}{l}\text { Rio das Cobras } \\
\text { (Campo do Dia) }\end{array}$ & $\begin{array}{l}\text { C.E.I. Feg Prag } \\
\text { Fernandes }\end{array}$ & 12 & 17 & 29 \\
\hline $\begin{array}{l}\text { Laranjeiras } \\
\text { do Sul }\end{array}$ & $\begin{array}{l}\text { Nova } \\
\text { Laranjeiras }\end{array}$ & $\begin{array}{l}\text { Rio das Cobras } \\
\text { (Taquara) }\end{array}$ & $\begin{array}{l}\text { E.E.I. José Ner } \\
\text { Nor Bonifacio }\end{array}$ & 6 & 6 & 12 \\
\hline $\begin{array}{l}\text { Laranjeiras } \\
\text { do Sul }\end{array}$ & $\begin{array}{l}\text { Nova } \\
\text { Laranjeiras }\end{array}$ & $\begin{array}{l}\text { Rio das Cobras } \\
\text { (Sede) }\end{array}$ & $\begin{array}{l}\text { E.E.I. Coronel } \\
\text { Nestor da Silva }\end{array}$ & 11 & 14 & 25 \\
\hline $\begin{array}{l}\text { Laranjeiras } \\
\text { do Sul }\end{array}$ & $\begin{array}{l}\text { Nova } \\
\text { Laranjeiras }\end{array}$ & $\begin{array}{l}\text { Rio das Cobras } \\
\text { (Lebre) }\end{array}$ & $\begin{array}{l}\text { C.E.I. Carlos } \\
\text { Alberto Cabreira } \\
\text { Machado }\end{array}$ & 7 & 22 & 29 \\
\hline $\begin{array}{l}\text { Laranjeiras } \\
\text { do Sul }\end{array}$ & $\begin{array}{l}\text { Laranjeiras } \\
\text { do Sul }\end{array}$ & Boa Vista & E.E.I. Ko Homu & 5 & 12 & 17 \\
\hline $\begin{array}{l}\text { Laranjeiras } \\
\text { do Sul }\end{array}$ & $\begin{array}{l}\text { Espigão Alto } \\
\text { do Iguaçu }\end{array}$ & $\begin{array}{l}\text { Rio das Cobras } \\
\text { (Pinhal) }\end{array}$ & $\begin{array}{l}\text { C.E.I. Valdomiro } \\
\text { Tupã Pires de } \\
\text { Lima }\end{array}$ & 4 & 18 & $\begin{array}{c}22 \\
\text { (continua) }\end{array}$ \\
\hline
\end{tabular}




\begin{tabular}{|c|c|c|c|c|c|c|}
\hline NRE & Município & Terra indígena & Escola & Indígenas & $\begin{array}{c}\text { Não- } \\
\text { indígenas }\end{array}$ & Total \\
\hline Londrina & Tamarana & $\begin{array}{l}\text { Apucaraninha } \\
\text { (Barreiro) }\end{array}$ & $\begin{array}{l}\text { E.E.I. Roseno } \\
\text { Vokrig Cardoso }\end{array}$ & 6 & 1 & 7 \\
\hline Londrina & Tamarana & $\begin{array}{l}\text { Apucaraninha } \\
\text { (Sede) }\end{array}$ & $\begin{array}{l}\text { E.E.I. João } \\
\text { Kavagtãn Vergílio }\end{array}$ & 23 & 2 & 25 \\
\hline Londrina & Tamarana & $\begin{array}{l}\text { Apucaraninha } \\
\text { (Sede) }\end{array}$ & $\begin{array}{l}\text { C.E.I. Benedito } \\
\text { Rokag }\end{array}$ & 7 & 12 & 19 \\
\hline Paranaguá & Paranaguá & Ilha da Cotinga & E.E.I. Pindoty & 2 & 6 & 8 \\
\hline Paranaguá & Guaraqueçaba & $\begin{array}{l}\text { Cerco Grande } \\
\text { Kuaray Oguatá } \\
\text { Porã }\end{array}$ & $\begin{array}{l}\text { E.E.I. Kuaray } \\
\text { Guatá Porã }\end{array}$ & 2 & 4 & 6 \\
\hline Pato Branco & Clevelândia & Alto Pinhal & E.E.I Nitotũ & 7 & 12 & 19 \\
\hline Pato Branco & Chopinzinho & $\begin{array}{l}\text { Ti Mangueirinha } \\
\text { (Palmeirinha) }\end{array}$ & E.E.I. Vera Tupã & 11 & 18 & 29 \\
\hline Pato Branco & Chopinzinho & $\begin{array}{l}\text { Ti Mangueirinha } \\
\text { (Fazenda) }\end{array}$ & E.E.I. Jykre Tãg & 13 & 14 & 27 \\
\hline Pato Branco & Mangueirinha & $\begin{array}{l}\text { Ti Mangueirinha } \\
\text { (Sede) }\end{array}$ & $\begin{array}{l}\text { C.E.I. Kókoj T ỹ } \\
\text { Han Já }\end{array}$ & 17 & 12 & 29 \\
\hline Pato Branco & Palmas & Palmas & $\begin{array}{l}\text { C.E.I Segsó Tanh } \\
\text { Sa }\end{array}$ & 12 & 16 & 28 \\
\hline $\begin{array}{l}\text { Telêmaco } \\
\text { Borba }\end{array}$ & Ortigueira & Queimadas & $\begin{array}{l}\text { E.E.I. Cacique } \\
\text { Crispin G ỹMũ }\end{array}$ & 9 & 16 & 25 \\
\hline $\begin{array}{l}\text { Telêmaco } \\
\text { Borba }\end{array}$ & Ortigueira & Mococa & $\begin{array}{l}\text { E.E.I. Cacique Nur } \\
\mathrm{Fe}\end{array}$ & 5 & 3 & 8 \\
\hline Toledo & $\begin{array}{l}\text { Diamante } \\
\text { D'Oeste }\end{array}$ & Tekoha Añetete & C.E.I. Kuaa Mbo’e & 9 & 16 & 25 \\
\hline Toledo & $\begin{array}{l}\text { Diamante } \\
\text { D'oeste }\end{array}$ & Itamarã & E.E.I. Araju Porã & 6 & 10 & 16 \\
\hline \multirow[t]{2}{*}{ Toledo } & Guaíra & $\begin{array}{l}\text { Tekoha } \\
\text { Marangatu }\end{array}$ & E.E.I. Mbyja Porã & 15 & 9 & 24 \\
\hline & & & Total & 353 & 522 & 875 \\
\hline
\end{tabular}

Fonte: SEED (2013)

Mas o que chama a atenção, conforme apontam muitos estudos na área e indicou Grupioni (2006, p. 64) na última citação mencionada (“a tão propalada participação indígena fica mais no discurso que na prática..."), é que o pequeno grupo de professores e pedagogos indígenas não tem voz na escola indígena, nem quando do seu estabelecimento (participando do processo de discussão sobre qual o formato de escola mais adequado para aquela comunidade e da elaboração do PPP, dentre outros), nem em seu processo de subsistência (na definição da distribuição das aulas, na oferta de atividades-extra, nas adequações de calendário etc.). E como o protagonismo indígena 
na escola é uma necessidade que não tem relação com a quantidade de indígenas presentes na instituição, sua participação efetiva deve ser garantida para que a escola seja adequada às necessidades e anseios da comunidade, pois

Todo projeto escolar só será escola indígena se for pensado, planejado, construído e mantido pela vontade livre e consciente da comunidade. O papel do Estado e outras instituições de apoio deve ser de reconhecimento, incentivo e reforço para este projeto comunitário. Não se trata apenas de elaborar currículos, mas de permitir e oferecer condições necessárias para que a comunidade gere sua escola. Complemento do processo educativo próprio de cada comunidade, a escola deve se constituir a partir dos seus interesses e possibilitar sua participação em todos os momentos da definição da proposta curricular, do seu funcionamento, da escolha dos professores que vão lecionar, do projeto pedagógico que vai ser desenvolvido, enfim, da política educacional que será adotada. Gersem dos Santos, professor Baniwa, AM (RCNEI, 1998, p. 25, grifos nossos).

Desse modo, no momento - e talvez ainda por um bom tempo - as escolas indígenas necessitam/necessitarão de professores não-indígenas para completar seus quadros.

Para o RCNEI (1998), a presença dos professores não-indígenas é considerada um problema, porque eles

[...] não possuem conhecimentos sobre os povos indigenas, provocando, portanto, distorções no processo ou impedindo o desenvolvimento da proposta de educação intercultural. Esta situação se deve, basicamente, ao fato de que, no Brasil, é difícil o acesso a informações adequadas sobre os povos indígenas. Sua divulgação fora do círculo dos pesquisadores e especialistas é ainda bastante deficitária, o que dificulta a plena compreensão do que seja a educação escolar indígena tal como se quer definir (BRASIL, 1998, p. 40-41, grifo nosso).

Segundo o documento, por desconhecer a realidade das comunidades indígenas, os professores não-indígenas podem impedir que o caráter intercultural da escola indígena se efetive. E inclusive a formação superior a que tiveram acesso contribui para esse desconhecimento, pois "[...] grande parte dos cursos oferecidos pelos estados e municípios [...] não oferecem uma abordagem consistente para a questão da interculturalidade e da diversidade linguística" (BRASIL, 1998, p. 42, grifo nosso).

E de que forma os professores não-indígenas poderiam ter uma formação mais consistente nesse sentido? No caso dos professores de língua, estes teriam de ter acesso a uma formação que lhes possibilitasse atuar em contextos linguisticamente complexos, que levasse em consideração a condição do Brasil de sabidamente ser um país multilíngue e multicultural, inclusive, segundo Oliveira (2000, p. 84), um dos mais multilíngues do mundo, em que se falam mais de duzentas línguas - 170 indígenas e 30, línguas de imigrantes.

Ressaltamos a importância de se considerar de fato a condição multilíngue/multicultural do país, pois até mesmo professores que atuam em escolas inseridas em comunidades reconhecidamente complexas em termos sociolinguísticos ${ }^{4}$

\footnotetext{
${ }^{4}$ Essas escolas têm Projetos Políticos Pedagógicos que possuem na grade curricular outras línguas, além do inglês e do espanhol, de caráter obrigatório (DALLA VECCHIA; FRAGA, 2012).
} 
relatam ter dificuldades em lidar pedagogicamente com alunos cujo bi/multilinguismo não é o esperado, o correto (DALLA VECCHIA, 2013), por não envolver apenas línguas majoritárias, mas também línguas desprestigiadas.

Em Fraga (2014), defendemos a importância de a formação inicial e continuada do licenciando/licenciado em Letras contemplar questões afetas às Políticas Linguísticas, considerando as exigências atuais que esses profissionais têm de atender (CORREA, 2010), as quais mudaram muito nos últimos vinte, quinze anos.

As questões que apontamos à época para justificar nosso ponto de vista partiam de nosso trabalho com alunos ingressantes nos cursos de licenciatura em Letras na Universidade Estadual de Ponta Grossa (UEPG). A convivência com esses alunos continua nos mostrando que são muitos os que temem se deparar com qualquer tipo de diversidade linguística "inesperada" na escola, apesar de muitos estudos e os próprios documentos oficiais, como os PCNs (1998), defenderem a importância de não se considerar a sala de aula brasileira como um espaço homogêneo linguisticamente, pois ele não é.

Nas palavras de Kramsch (2012), atualmente é mais do que desejável que o professor tenha "uma visão multilíngue". É imprescindível que todo docente, especialmente o de língua, tenha uma visão do seu objeto de ensino que não inclua somente a visão tradicional, seja a normativa ou a linguístico-formalista, aquela que "dividiu as práticas linguísticas em objeto e seu sobejo, performativamente inventou a "língua" como um fato, ao mesmo tempo científico e nacionalista, e empurrando a prática/ação para fora dos limites dos estudos linguísticos" (PINTO, 2010, p. 71, grifos da autora).

Mas como formar professores de língua para atuar de forma adequada em contextos sociolinguisticamente complexos? E qual é ou deveria ser o papel do curso de licenciatura em Letras nesse sentido?

Segundo Correa (2010, p. 40-41, grifo nosso):

[...] é necessário observar como funcionam as políticas linguísticas, trazendo-as para o centro do debate. Entre os muitos conhecimentos, que são exigidos daqueles que estão em fase de formação para atuar como docentes e como pesquisadores e também dos que já estão formados e atuando em sala de aula, termos como planejamento linguístico, norma culta, norma padrão, acordo ortográfico, entre outros afetos aos estudos da linguagem, precisam tornar-se palavras ou expressões significativas, por assim dizer, passíveis de reflexões mais aprofundadas. Dessa forma, é possível contextualizar melhor as escolhas linguísticas, os panoramas plurilíngues, os contextos de variação linguística, e também a defesa das configurações monolíngues e homogêneas, incluindo as exigências de domínio das regras que fazem parte de tais configurações.

Pela citação, observa-se que a autora manifesta-se favorável, portanto, a que o professor de língua, em formação ou formação continuada, perceba a "configuração dos ambientes linguísticos" (CORREA, 2010, p. 40) também pelo viés político, por meio de discussões sistemáticas sobre políticas linguísticas. Por outro lado, é possível que as diferentes instituições de ensino superior escolham o melhor formato para realizar essas discussões, formato esse que poderia variar desde a oferta de uma disciplina inteiramente dedicada à temática ou a inserção de conteúdos relativos ao assunto dentro 
de outras disciplinas, dentre outras possibilidades. O importante é que os debates permitam aos professores em formação inicial e continuada compreender que:

[...] as exigências encontradas no sistema escolar derivam das ações de intervenção nas línguas e ter conhecimento de tais ações pode elucidar muitos paradoxos relativos à necessidade de conviver com e transitar pela diversidade, a heterogeneidade e as exigências que vêm impostas por meio de uma visão homogênea e estática de linguagem e cultura (CORREA, 2010, p. 41).

O levantamento inicial de dados que realizamos no referido texto de 2014 nos permitiu concluir que a discussão sobre políticas linguísticas em formato de disciplina que se dedica sistematicamente à temática ainda é bastante rara e, quando acontece, é mais comum que ela se dê em âmbito de pós-graduação ${ }^{5}$ (não apenas em programas da área de Letras e Linguística, mas também de outras áreas de conhecimento, como Educação). Já o formato mais frequente é o da discussão sobre políticas linguísticas como conteúdo pertinente às disciplinas ofertadas por programas de pós-graduação (não só da área de Letras e Linguística, mas também de outras áreas, como Educação, Antropologia e Ciências Sociais). Além disso, embora pouco comum, saliente-se que já há alguns cursos de graduação que oferecem a disciplina em suas grades curriculares, seja em caráter obrigatório ou eletivo.

Já naquele texto, o que se pôde concluir a partir dos dados levantados é que a discussão sobre a temática das políticas linguísticas era - e ainda é - incipiente em âmbito nacional, mas na UEPG, no currículo do curso de licenciatura em Letras implantado em 2015, o corpo docente já abriu espaço para tal no formato de disciplina ${ }^{6}$, por considerar, a partir de discussões iniciadas em 2012, que a inserção desta disciplina era necessária.

Enfim, tendo em vista a situação real da educação brasileira, mais especificamente a das escolas indígenas, concluímos que é fundamental investir qualitativamente na formação do professor. No caso dos professores de língua não indígenas, repensando os currículos das licenciaturas, de modo que estes possibilitem acesso a uma visão que considere a "[...] interculturalidade e [a] diversidade linguística" brasileiras (BRASIL, 1998, p. 42). Já em relação aos professores indígenas, nos estados em que estes cursos ainda não existem, propondo a oferta de licenciaturas interculturais para que estes tenham mais oportunidades de acesso ao ensino superior.

\footnotetext{
${ }^{5}$ Inclusive no programa de Mestrado em Linguagem, Identidade e Subjetividade da UEPG, com o título de "Políticas Linguísticas", com a ementa: "A origem da Política linguística. As tipologias das situações plurilíngues. Política Linguística versus Planificação Linguística. Os instrumentos da planificação linguística. Panorama histórico das Políticas Linguísticas no Brasil: línguas indígenas, língua geral, línguas de imigração, o português e sua gestão escolar, a política de línguas estrangeiras. Estudos de Caso".

${ }^{6}$ A disciplina se chama "Políticas linguísticas e ensino de língua" e tem a seguinte ementa: "Principais aportes teóricos ligados ao campo das Políticas Linguísticas. Conexões com o ensino de língua” (UEPG, 2015).
} 


\section{REFERÊNCIAS}

AMARAL, W. R. do. As trajetórias dos estudantes indígenas nas Universidades Estaduais do Paraná: sujeitos e pertencimentos. 2010. 594 f. Tese (Doutorado em Educação) - Setor de Educação, Universidade Federal do Paraná, Curitiba, 2010.

AMARAL, W. R. do; FRAGA, L.; RODRIGUES, I. C. (Org.). Universidade para indígenas: a experiência do Paraná. v. 1. Rio de Janeiro: FLACSO, GEA; UERJ, LPP, 2016.

BRASIL. Constituição da República Federativa do Brasil. Diário Oficial da União, Brasília, 1988.

BRASIL. IBGE - Instituto Brasileiro de Geografia e Estatística. Os indígenas no Censo Demográfico 2010. Primeiras considerações com base no quesito cor ou raça. Rio de Janeiro, 2012.

BRASIL. Lei n. 9394 de 20 de dezembro de 1996. Brasília, 1996. Disponível em: $<$ http://portal.mec.gov.br/arquivos/pdf/ldb.pdf $>$. Acesso em: 16 set. 2016.

BRASIL. Ministério da Educação. Referencial Curricular Nacional para Escolas Indigenas. Brasília: Brasília: MEC/SEF, 1998. Disponível em: <http://url20.ca/8PH>. Acesso em: 03 de jan. 2011.

CAVALCANTI, M. C. Estudos Sobre Educação Bilíngue Escolarização em Contextos de Minorias Linguísticas no Brasil. D.E.L.T.A., v. 15, p. 385-417, 1999. Disponível em: $<$ http://www.scielo.br/scielo.php?pid=S0102-44501999000300015\&script=sci_arttext $>$. Acesso em: 03 de jan. 2011.

CORREA, D. A. Política linguística e o curso de licenciatura em Letras: um estudo inicial sobre o PEC-G. Linguagem em Foco, n. 1, v. 1, p. 39-52, 2010.

DALLA VECCHIA, A. Politicas linguísticas na colônia "alemã" de Entre Rios: o papel do Colégio Imperatriz Dona Leopoldina. 2013. 187 f. Dissertação (Mestrado em Linguagem, Identidade e Subjetividade) - Setor de Ciências Humanas, Letras e Artes, Universidade Estadual de Ponta Grossa, Ponta Grossa, 2013.

DALLA VECCHIA, A.; FRAGA, L. A construção da identidade de grupo na colônia Entre Rios: práticas de letramento na Educação Infantil. Revista Interfaces, v. 3, p. 1322, 2012.

FRAGA, L. Políticas linguísticas na formação do licenciado em letras: uma discussão introdutória. In: CORREA, D. A. (Org.). Política linguística e ensino de língua. Campinas: Pontes Editores, 2014. p. 45-58.

FRAGA, L.; TASSO, I. E. V. de S.; RODRIGUES, I. C.; AMARAL, W. R. do; NOVAK, M. S. J. Políticas afirmativas para populações indígenas no Paraná: da promulgação da Lei Estadual 13.134/2001 à proposta de elaboração de um curso de licenciatura e/ou pedagogia intercultural. Projeto submetido ao Edital de Convocação SECADI/SETEC/SESu/FNDE $n^{\circ}$ 02, de agosto de 2013. 2014. 
FRAGA, L.; TASSO, I. E. V. S.; KASTELIC, E. S. D. A realidade linguística das comunidades indígenas do Paraná. In: AMARAL, W. R. do; FRAGA, L.; RODRIGUES, I. C. (Org.). Universidade para indígenas: a experiência do Paraná. v. 1. Rio de Janeiro: FLACSO/LPP-UERJ, 2016. p. 157-170.

GRUPIONI, L. D. B. Contextualizando o campo da formação de professores indígenas no Brasil. In. GRUPIONI, L. D. B. (Org.). Formação de professores indígenas: repensando trajetórias. Brasília: Ministério da Educação, Secretaria de Educação Continuada, Alfabetização e Diversidade, 2006. p. 39-68.

KONDO, R. H. Representações e atitudes linguísticas na (re)construção da identidade indígena dos Guarani do pinhalzinho (Tomazina/PR): um estudo na escola "YVY PORÃ". 2013. 200 f. Dissertação (Mestrado em Linguagem, Identidade e Subjetividade) - Setor de Ciências Humanas, Letras e Artes, Universidade Estadual de Ponta Grossa, Ponta Grossa, Paraná, 2013.

KRAMSCH, C. Why foreign language teachers need to have a multilingual outlook and what that means for their teaching practice. Muitas Vozes, Ponta Grossa, n. 1, v. 2, p. 182, ago. 2012.

OLIVEIRA, G. M. de. O que quer a linguística e o que se quer da linguística - a delicada questão da assessoria linguística no movimento indígena. In: Cadernos Cedes 49 - Educação indígena e interculturalidade. CEDES, 2000.

PARANÁ. Secretaria de Estado da Ciência, Tecnologia e Ensino Superior. Lei $n^{o}$ 13.134, de 18/04/2002. Reserva três vagas para serem disputadas entre os índios integrantes das sociedades indígenas paranaenses, nos vestibulares das universidades estaduais. In: Diário Oficial, n. 5969. Curitiba, 19/04/2002.

PINTO, J. P. Da língua-objeto à práxis linguística: desarticulações e rearticulações contra hegemônicas. Linguagem em foco: Revista do programa de pós-graduação em Linguística Aplicada da UECE, Fortaleza: EDUECE, v. 2, n. 2, p. 69-83, 2010.

UNIVERSIDADE ESTADUAL DE PONTA GROSSA. RESOLUÇÃO CEPE Nº 014, DE 31 DE MARÇO DE 2015. Aprova novo projeto pedagógico do curso de licenciatura em Letras português/inglês, da UEPG. Disponível em: $<$ http://www.uepg.br/cepe/atosoficiais/2015/014.pdf $>$. Acesso em: 30 set. 2016.

UNIVERSIDADE ESTADUAL DE PONTA GROSSA. RESOLUÇÃO CEPE No 015 , DE 31 DE MARÇO DE 2015. Aprova novo projeto pedagógico do curso de licenciatura em Letras português/francês, da UEPG. Disponível em: $<$ http://www.uepg.br/cepe/atosoficiais/2015/015.pdf>. Acesso em: 30 set. 2016.

UNIVERSIDADE ESTADUAL DE PONTA GROSSA. RESOLUÇÃO CEPE No 016, DE 31 DE MARÇO DE 2015. Aprova novo projeto pedagógico do curso de licenciatura em Letras português/espanhol, da UEPG. Disponível em: $<$ http://www.uepg.br/cepe/atosoficiais/2015/016.pdf >. Acesso em: 30 set. 2016.

Recebido em: 17/10/2016

Aprovado em: 29/11/2016 